\title{
Descending pain modulation and chronification of pain
}

\author{
Michael H. Ossipov, Kozo Morimura, and Frank Porreca \\ Department of Pharmacology, Arizona Health Sciences Center, University of Arizona, Tucson, \\ Arizona, USA
}

\section{Abstract}

Purpose of review-Chronic pain is an important public health problem that negatively impacts quality of life of affected individuals and exacts an enormous socio-economic cost. Currently available therapeutics provide inadequate management of pain in many patients. Acute pain states generally resolve in most patients. However, for reasons that are poorly understood, in some individuals, acute pain can transform to a chronic state. Our understanding of the risk factors that underlie the development of chronic pain is limited. Recent studies have suggested an important contribution of dysfunction in descending pain modulatory circuits to pain 'chronification'. Human studies provide insights into possible endogenous and exogenous factors that may promote the conversion of pain into a chronic condition.

Recent findings-Descending pain modulatory systems have been studied and characterized in animal models. Human brain imaging techniques, deep brain stimulation and the mechanisms of action of drugs that are effective in the treatment of pain confirm the clinical relevance of topdown pain modulatory circuits. Growing evidence supports the concept that chronic pain is associated with a dysregulation in descending pain modulation. Disruption of the balance of descending modulatory circuits to favour facilitation may promote and maintain chronic pain. Recent findings suggest that diminished descending inhibition is likely to be an important element in determining whether pain may become chronic. This view is consistent with the clinical success of drugs that enhance spinal noradrenergic activity, such as serotonin/norepinephrine reuptake inhibitors (SNRIs), in the treatment of chronic pain states. Consistent with this concept, a robust descending inhibitory system may be normally engaged to protect against the development of chronic pain. Imaging studies show that higher cortical and subcortical centres that govern emotional, motivational and cognitive processes communicate directly with descending pain modulatory circuits providing a mechanistic basis to explain how exogenous factors can influence the expression of chronic pain in a susceptible individual.

Summary-Preclinical studies coupled with clinical pharmacologic and neuroimaging investigations have advanced our understanding of brain circuits that modulate pain. Descending pain facilitatory and inhibitory circuits arising ultimately in the brainstem provide mechanisms that can be engaged to promote or protect against pain 'chronification'. These systems interact

\section{(C) 2014 Wolters Kluwer Health | Lippincott Williams \& Wilkins}

Correspondence to Frank Porreca, Department of Pharmacology, College of Medicine, University of Arizona, Tucson, AZ 85724 USA. Tel: +(520) 626 7421; fax: (520) 626 4182; frankp@email.arizona.edu.

Conflicts of interest

No conflicts of interest. 
with higher centres, thus providing a means through which exogenous factors can influence the risk of pain chronification. A greater understanding of the role of descending pain modulation can lead to novel therapeutic directions aimed at normalizing aberrant processes that can lead to chronic pain.

\section{Keywords}

chronic pain; descending inhibition; noradrenergic pain inhibition; pain modulation

\section{INTRODUCTION}

There is little argument that chronic pain represents an urgent medical need worldwide [1]. Chronic pain is consistently reported as one of the most frequent complaints driving patients to seek medical attention [2]. It exerts a high socio-economic cost, estimated to be between US\$560 and US\$635 billion annually in terms of healthcare costs and lost productivity [3]. The reported prevalence of chronic pain varies widely. In the USA, estimates of chronic pain prevalence ranged from a low of 15 [4] to a high of 64\% [5], a range likely resulting from differences in data collection methods. Similarly, wide ranges in chronic pain prevalence were found when surveys were performed globally (from 2 to 55\%) or in Europe (from 5 to 33\%) [2]. In a recent internet-based study performed in the USA, 9326 respondents indicated chronic pain satisfying the International Association for the Study of Pain definition [2]. Of these, two-thirds had medically diagnosed conditions, with low back pain, osteoarthritis, rheumatoid arthritis and migraine headache accounting for 18, 16, 6 and $3 \%$, respectively, of the total prevalence [2]. In spite of its prevalence, chronic pain is inadequately managed with treatment success rates of only about $30 \%$ [6].

\section{THE VARIABILITY OF CHRONIC PAIN}

The large variability among published reports of the prevalence of chronic pain suggests that there is considerable fluidity in the manifestation of this condition. Indeed, this argument is strengthened when one considers the profound differences in vulnerability of individuals to

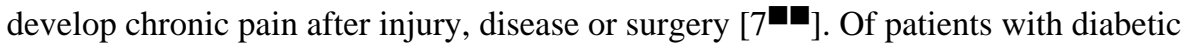
neuropathy, only one-third developed painful diabetic neuropathy [8]. In a study of 15692 diabetic patients in England, 26\% of patients without neuropathy reported pain as did 60\% of those with severe neuropathy [8]. In that study, it was found that incidence of pain increased with age, and that women had a 50\% greater chance of developing chronic pain than did men. Approximately one-third of patients with low back pain develop persistent pain that lasts over 1 year [9]. The risk of developing chronic pain after surgery, or persistent postsurgical pain (PPP), ranges from 5 to $50 \%$ of surgical patients, and between 2 and $10 \%$ of these develop severe pain [7 $\left.{ }^{\square}, 10-12\right]$. Although hernia repair and Caesarian section are associated with a $10 \%$ incidence of PPP, the risk of PPP after mastectomy, thoracotomy or amputation is 30,40 and $50 \%$, respectively [7.]. It appears that the likelihood of developing chronic PPP is related more to the intensity of the acute pain felt immediately post-operatively, rather than to the procedure itself [12]. No correlation has been identified between the degree of joint damage and intensity of pain in patients with osteoarthritis $\left[7^{\mathbf{W}}\right.$ ]. Complex regional pain syndrome (CRPS) is a disabling chronic pain 
condition, yet it may be provoked by injury as apparently trivial as venipuncture $[13,14]$, by other neurologic insults or by postherpetic neuralgia (PHN) and by mild or nonapparent zoster (i.e. sine herpete) [15]. In a recent review of CRPS, about one-half of patients who developed PHN of the arms or legs eventually showed signs of CRPS, whereas none who had PHN of the head or neck did so [15]. It was concluded that CRPS represents an 'endophenotype' arising from even minor injury in susceptible individuals [15].

The mechanisms that drive the development of chronic pain and the potential risk factors that may predispose an individual to a chronic pain state are largely unknown. Andersen and Kehlet [16] found that radiotherapy and nerve damage were risk factors for postmastectomy persistent pain, but inconsistencies among studies prevented the identification of other clear risk factors. It was suggested that future studies include factors such as age, weight, ethnicity and socioeconomic status, as well as preoperative pain, nociceptive function and psychosocial factors [16]. A more recent investigation by the same team found that demographic factors, surgical methods and treatment-related variables were less important in the development of postmastectomy persistent pain than psychosocial variables such as catastrophizing, somatization, sleep, anxiety and depression [17 ]. In a prospective study of patients undergoing breast cancer surgery, Sipila et al. [18 ${ }^{\mathbf{m}}$ ] developed a diagnostic tool to aid in the prediction of development of persistent pain employing six factors: previous chronic pain of any kind, high number of previous operations, preoperative pain in the area to be operated, high BMI, previous smoking and older age [18 ${ }^{\mathbf{m}}$ ]. An epidemiologic study of chronic pain in Europe suggested that risk factors include sex, age, cultural background and attitudes about pain [19 $]$. Although increased age is associated with an increased risk of PHN, young age is a risk factor for PPP [ $\left.7^{-1}, 10,11\right]$. It is generally agreed that the risks of developing chronic pain include genetic predispositions and prior exposures to injury, as well as psychosocial factors that are less readily identified such as catastrophizing, social support, economic status, pain expectation and past experiences $\left[\mathbf{m}^{\mathbf{m}}, 10,11\right]$.

Recent advances in neuroimaging techniques and computational analysis have enabled investigators to noninvasively evaluate the brain function in individuals and patients increasing our understanding of the circuits underlying perception of pain. Numerous imaging studies have indicated that noxious stimuli activate several key brain regions, including cortical sites and limbic structures associated with emotional processing [20-22]. Moreover, neuroimaging studies have also shown that chronic pain may be accompanied by alterations in structural features, functional connectivity or activity of these sites [23-26]. Although these brain regions are generally associated with emotional systems, they also interact with structures that encode descending pain modulation [7 $\mathbf{m}^{\mathbf{m}}$ ].

Activation of nociceptors by stimuli that can potentially elicit tissue damage engages broad neural networks in the brain that reflect the meaningful experience of pain from sensory input. In addition to its sensory components, pain is also associated with a powerful affective component [27 28,29$]$. Given the emotional or affective contributions to the pain experience, it is not surprising that chronic pain patients suffer from psychological and sociologic complications that are a further burden in addition to the already existing pain [30,31]. As pain progresses from an acute origin, as from an injury or surgery, to a chronic condition, the negative emotional states associated with chronic pain not only exacerbate 
physiological pain sensitivity [32 $]$ but also increase the incidence of comorbidities such as depression, anxiety, sleep disturbance, decision-making abnormalities and can even increase the risk for suicide $[33,34 \mathbf{\square}$. In spite of its prevalence and impact on patients' lives and on society, chronic pain is still poorly managed and current therapies provide inadequate relief $[35,36]$. Therefore, increased understanding of mechanisms that may drive chronic pain, including those that address the affective aspects of pain, are key factors in the development of new therapies for clinical management of chronic pain.

\section{PAIN PROCESSING IN BRAIN}

The advances in neuroimaging techniques seen within the past 2 decades have led to a virtual explosion in the numbers of studies on the human brain's activity under conditions of acute pain and chronic pain. These noninvasive techniques have provided corroborative evidence that brain regions found to contribute to pain processing and modulation by pharmacologic or electrophysiologic means in animal studies correspond to regions of the human brain that are responsive to pain. In addition, these investigations have also shown that pain activates a network of brain regions affecting somatosensory and emotional aspects.

\section{Sites activated by noxious stimulation}

Neuroimaging studies have led to the identification of brain regions activated by noxious stimuli, including the primary somatosensory cortex (S1), secondary somatosensory cortex (S2), anterior cingulate cortex (ACC), prefrontal cortex (PFC), insula, amygdala, thalamus, cerebellum and the mesolimbic reward circuit, which includes the ventral tegmental area (VTA) and nucleus accumbens (NAc) [20,37,38 $]$. The somatosensory cortices (S1 and S2) and the insula are believed to encode the sensory features of pain, which include quality (stinging, burning or aching), location and duration [37,38 39$]$. The prefrontal region and the limbic system (ACC, PFC, amygdala, VTA and NAc) encode emotional and motivational responses, and are implicated in the affective and contextual aspect of pain $[37,38,39]$. It is important to emphasize that these regions are not selectively or exclusively activated by nociception or restricted solely to pain perception. Rather, regions serving several neurological functions including cognition, emotion, motivation and sensation are functionally connected in the context of nociception and give rise to the experience of pain $[39,40]$. The interactions among these sites also provide a means whereby emotional and motivational cues can alter the experience and perception of pain through interactions with the descending pain modulatory system $\left[7^{\mathbf{m}}, 41\right]$.

\section{DESCENDING PAIN MODULATION}

Numerous investigations over the past half-century have established that activation of midbrain and medullary sites can exert bidirectional control over nociception. The periaqueductal gray (PAG) receives inputs from higher brain centers and is capable of activating a powerful analgesic effect. The rostroventromedial medulla (RVM) can both facilitate or inhibit nociceptive inputs and acts as a final relay in the control of descending pain facilitation. These structures provide a mechanism through which cortical and subcortical sites can influence nociception. 


\section{Periaqueductal gray and rostroventromedial medulla}

The periaqueductal gray (PAG) is the first brain region to have been explicitly demonstrated to activate an endogenous pain inhibitory system. Early studies showed that microinjection of opioids or electrical stimulation applied into this region elicited a powerful antinociceptive effect in animals [42,43] and humans [44-46]. Analgesia produced by PAG stimulation or microinjection of opioids is naloxone-reversible [44,47-50]. It is now well established that the PAG is a source of descending opioid-mediated inhibition of nociceptive inputs [47,51,52]. This region receives inputs from cortical sites and has reciprocal connections with the amygdala [53,54] as well as ascending nociceptive inputs from the spinal dorsal horns by way of the parabrachial nuclei [54]. Imaging studies in human volunteers showed that the rostral ACC (rACC) likely mediates expectation and placebo analgesia by activation of the PAG [55,56]. The PAG influences descending pain modulation primarily through its reciprocal connections with the rostroventromedial medulla (RVM) [57]. For example, excitation of PAG neurons also excites the activity of RVM neurons and is associated with inhibition of nocifensive reflexes in the rat [58]. The PAG is therefore well localized to modulate nociceptive inputs and pain perception through its interactions with ascending and descending projections from numerous sites.

The RVM includes the serotonergic nucleus raphe magnus (NRM), the nucleus reticularis gigantocellularis-pars alpha and the nucleus paragiganto-cellularis lateralis [57,59]. In addition to the PAG, the RVM also receives inputs from the thalamus, the parabrachial region and the noradrenergic locus coeruleus, and is considered to be the final common relay in descending modulation of pain, projecting to the spinal dorsal horns as well as the trigeminal nucleus caudalis $[57,59,60]$. The RVM exerts a bidirectional pain modulatory effect, both inhibiting and facilitating pain. Early studies identified 'on-cells' that increased their activity in response to noxious stimuli and prior to a nociceptive reflex, whereas 'offcells' ceased firing immediately prior to the tail-flick [57,59,60]. Moreover, opioids inhibit on-cells and cause excitation of off-cells, and the latter effect is considered 'necessary and sufficient' to produce analgesia [57,60]. The existence of on-cells and off-cells with descending projections to the spinal dorsal horns provides a neuronal context for positive and negative pain modulation from the PAG/RVM system [60]. Moreover, as this system receives inputs from higher cortical sites, it also provides a mechanism whereby homeostatic or existential priorities may tone down or augment nociceptive inputs [60]. Finally, it is also suggested that an imbalance between the inhibitory and facilitatory descending pain modulatory systems may underlie pathological pain states $\left[7^{\boldsymbol{\square}}, 10,17 \boldsymbol{\square}, 60\right]$. Numerous studies performed in animal models of neuropathic or inflammatory pain support this view. Injury or inflammation enhance RVM on-cell activity, and pharmacological, neurochemical or physical disruption of descending facilitation from the RVM has abolished enhanced behavioural responses to evoked stimuli without attenuating acute, protective nociceptive reflexes [61-67]. More recently, inhibition of the RVM by microinjection of local anaesthetics reversed ongoing pain in models of neuropathic pain and of migraine $\left[68,69^{\mathbf{m}}\right]$. Importantly, a recent imaging study with humans showed that activation of this region is specifically related to development and maintenance of central sensitization [70]. 


\section{Spinal serotonergic activity modulates pain}

The RVM includes major serotonergic nuclei, the NRM and the NpGC, as well as GABAergic and glycinergic neuronal populations, all of which have descending projections to the spinal cord [71-76]. However, there is conflicting evidence regarding the nature of oncells and off-cells viz-a-viz neuro-transmitter content, and whether these neurons are indeed serotonergic, nonserotonergic or represent mixed populations [71-76]. Sufficient evidence exists to indicate that activation of descending projections from the RVM elicits release of serotonin in the spinal dorsal horns, either from terminals of direct projections or from spinal interneurons [71-76]. However, spinal 5-hydroxytryptamine (5-HT) can be pronociceptive or antinociceptive, depending on the 5-HT receptor subtype activated. Thus, activation of the 5- $\mathrm{HT}_{1 \mathrm{~A}}, 5-\mathrm{HT}_{1 \mathrm{~B}}, 5-\mathrm{HT}_{1 \mathrm{D}}$ and $5-\mathrm{HT}_{7}$ receptors tends to be antinociceptive, whereas the $5-\mathrm{HT}_{2 \mathrm{~A}}$ and $5-\mathrm{HT}_{3}$ receptor tend to promote nociception [77-82]. Antinociception in mice produced by RVM morphine was blocked by spinal $5-\mathrm{HT}_{7}$ antagonist and hyperalgesia produced by RVM CCK was blocked by a spinal 5- $\mathrm{HT}_{3}$ antagonist [78]. In other studies in mice, systemic $5-\mathrm{HT}_{7}$ agonists blocked hyperalgesia, whereas $5-\mathrm{HT}_{7}$ antagonists elicited enhanced pain [83]. Taken together, these observations indicate an important serotonergic role for bidirectional pain modulation.

\section{Descending noradrenergic pain modulation}

Descending noradrenergic projections to the spinal dorsal horns arise from the A5, the locus coeruleus (A6) and the Kölliker-Füse (A7) pontine noradrenergic nuclei, and these regions communicate with the RVM and PAG [84-87]. Thus, these noradrenergic projections form an important component of descending pain modulation. Numerous animal studies showed that chemical or electrical stimulation of the noradrenergic nuclei, as well as the PAG or RVM, released norepinephrine into spinal cerebrospinal fluid and produced antinociception that was blocked by spinal a2-adrenergic receptor antagonists [87]. Activation of spinal $a_{2}-$ adrenergic receptors can inhibit nociceptive transmission both presynaptically and postsynapticically $[87,88]$. Spinally administered $\mathrm{a}_{2}$ adrenergic agonists produce a strong antinociceptive effect $[87,89,90]$, and show a strong antinociceptive synergy with opioids [87,89-91]. In contrast to the spinal $a_{2}$-adrenergic receptors, activation of spinal $a_{1^{-}}$ adrenergic receptors shows a pain facilitatory effect [92]. Spinal administration of $\mathrm{a}_{2}{ }^{-}$ adrenergic agonists produce analgesia in humans as well $[93,94]$.

Recent studies suggest that the activity of the descending noradrenergic system is augmented in conditions of nerve injury in an effort to compensate for enhanced nociceptive inputs [95]. Injury is associated with increased synthesis and release of norepinephrine along with an enhanced efficacy of spinal $a_{2}$-adrenergic receptors [95]. Enhanced efficiency of this system was found to underlie the increased efficacy of spinal clonidine against behavioral signs of neuropathic pain in animal models [96,97]. Enhanced spinal noradrenergic efficiency in injury or inflammation also provides a mechanistic basis for the clinical success of the serotonin/norepinephrine reuptake inhibitors (SNRIs) duloxetine and milnacipran in diabetic neuropathy, fibromyalgia and osteoarthritis [98-100]. Tapentadol and tramadol are analgesics with multifunctional mechanisms involving differing degrees of agonist activity at the m-opiate receptor and inhibition of norepinephrine reuptake [101 $\mathbf{m}$ ]. 
This dual action is believed to result in an $a_{2}$-adrenergic/opiate synergy accounting for the success of these drugs in chronic pain [101 $\mathbf{m}$ ].

\section{DYSREGULATION OF DESCENDING PAIN MODULATION MAY PROMOTE AND MAINTAIN CHRONIC PAIN}

It is believed that descending pain facilitatory and inhibitory systems function in concert, thus maintaining a baseline state of sensory processing [59,102]. Illness, injury or inflammation can perturb this balance, and if facilitation is favoured, enhanced pain is manifest, whereas an increase in inhibition can mask an underlying enhanced pain state, in effect maintaining a homeostatic state $[59,102,103]$. Xu et al. [104] had found that about $30 \%$ of Sprague-Dawley rats did not develop behavioural signs of neuropathic pain (i.e. tactile and cold allodynia) after spinal nerve ligation (SNL). The systemic or spinal administration of the $a_{2}$-adrenergic receptor antagonist atipamezole, but not of naloxone, to these animals resulted in expression of tactile and cold allodynia. Importantly, the responses of rats that did show these signs initially were not exacerbated by atipamezole [104]. It was suggested that a tonic endogenous noradrenergic inhibitory control prevented expression of signs of enhanced pain so that lifting of the inhibition unmasked the enhanced pain state [104]. A recent study [105] evaluated the consequences of SNL surgery on behavioural signs of neuropathic pain in Holtzman rats; SNL produced allodynia in approximately onehalf of these injured rats. In rats demonstrating allodynia due to nerve injury, blockade of RVM activity with lidocaine reversed both evoked hypersensitivity and produced conditioned place preference (CPP) revealing the presence of ongoing pain. Remarkably, in SNL rats that were not demonstrating evoked hypersensitivity (i.e. presumably 'pain-free'), RVM lidocaine precipitated allodynia and produced conditioned place aversion (CPA) [105]. Moreover, selective inhibition of pain inhibitory neurons of the RVM with the $\kappa-$ opioid agonist U69593 or spinal administration of the $\alpha_{2}$-adrenergic antagonist yohimbine also unmasked signs of enhanced pain in asymptomatic nerveinjured rats [105]. Electrophysiologic studies suggested that these 'pain-free' injured rats had a reduced functioning of RVM on-cells and enhanced function of RVM off-cells [105]. These results suggest that engagement of descending inhibition can protect against development of experimental neuropathic pain following injury, and that enhanced pain appears when descending inhibition is attenuated [105]. Most recently, studies performed with tibial nerve transection in rats found that descending noradrenergic inhibition delays the expression and extent of enhanced pain [106 ${ }^{\mathbf{m}}$ ]. Blockade of spinal $a_{2}$-adrenergic receptors hastened the onset of behavioural sensitization as well as the onset of contralateral allodynia and enhanced Fos expression in the spinal dorsal horn [106 ${ }^{\mathbf{m}}$ ]. Collectively, these studies indicate that an intact and effective descending noradrenergic pain inhibitory system protects against the development of enhanced abnormal pain and that an imbalance between pain inhibition and facilitation can lead to enhanced abnormal pain.

The clinical implications of these observations are that individuals with dysfunction or attenuation of endogenous pain inhibition may be more likely to develop chronic pain. One example is that individuals with pancreatic cancer normally report pain only after the cancer has advanced to a late stage, most likely because the disease progression overwhelms 
descending inhibition [107]. A similar delay in enhanced pain responses is seen in a mouse model of pancreatic cancer, in which systemic naloxone administration unmasks pain when administered at early stages [107]. Several studies with humans support the concept that dysfunctional pain states or chronic pain may be due to a deficit in endogenous descending pain inhibitory systems, manifested as a loss of conditioned pain modulation (CPM) $[108,109-111]$. Dysfunction of endogenous pain inhibition has been demonstrated in patients with fibromyalgia, irritable bowel syndrome, temporomandibular disorder, osteoarthritis, chronic pancreatitis and rheumatoid arthritis, and has reportedly been used to predict postsurgical pain [112 -116 $\left.\mathbf{\square}^{\mathbf{a}}, 117,118\right]$. In animals, loss of diffuse noxious inhibitory controls (DNICs) has been demonstrated with electrophysiologic studies in rats in which application of a noxious stimulus reduced or abolished an initial nociceptive response [119]. Additional studies showed that DNIC is integrated at the level of the dorsal reticular nucleus (DRt), which communicates with the PAG and RVM and projects to the spinal cord $[120,121]$. Loss of DNIC was produced by persistent morphine exposure in rats, resulting in increased sensitivity to sensory stimuli of trigeminal neurons sensitive to dural stimulation [122]. Importantly, DNIC was restored in these animals by inactivating the RVM with lidocaine [122]. This study suggests that enhanced descending facilitation may appear as a loss of inhibition. Consequently, it is not clear which of these alterations in pain modulation are more important clinically.

\section{CONCLUSION}

Significant advances have been made in our understanding of endogenous mechanisms that detect and interpret acute, nociceptive pain. In contrast, the processes that lead to the development of chronic pain conditions remain obscure and incompletely understood. The need for advancement in this aspect of pain research is clear, as chronic pain remains a critical unmet clinical need. Imaging studies have begun to reveal those brain regions that may undergo neuroplastic changes leading to chronic pain, as have studies on functional connectivity. Baliki et al. [24] have demonstrated that the strength of the functional connectivity between the medial PFC and NAc predicts patients who will develop chronic low back pain with greater than $80 \%$ accuracy. Understanding of interaction between higher brain sites, such as those related to emotional learning with descending pain modulatory systems, is likely to reveal significant insights into mechanisms of chronification. Data support the apparent loss of net descending inhibition as a mechanism that promotes chronic pain while engagement of inhibition protects against chronic pain. Why different individuals may fail to engage descending protective mechanisms is not understood and requires further investigation. Understanding the role of descending modulatory circuits in pain chronification may lead to the discovery of new therapeutics.

\section{Acknowledgements}

Supported by: NIH grants NS066958 and DA034975.

\section{REFERENCES AND RECOMMENDED READING}

Papers of particular interest, published within the annual period of review, have been highlighted as: 
of special interest

of outstanding interest

1. Tsang A, Von Korff M, Lee S, et al. Common chronic pain conditions in developed and developing countries: gender and age differences and comorbidity with depression-anxiety disorders. J Pain. 2008; 9:883-891. [PubMed: 18602869]

2. Johannes CB, Le TK, Zhou X, et al. The prevalence of chronic pain in United States adults: results of an internet-based survey. J Pain. 2010; 11:1230-1239. [PubMed: 20797916]

3. Institute of Medicine Committee on Advancing Pain Research C, Education. Relieving pain in America: a blueprint for transforming prevention, care, education, and research. National Academies Press (US); Washington, DC: 2011.

4. Hardt J, Jacobsen C, Goldberg J, et al. Prevalence of chronic pain in a representative sample in the United States. Pain Med. 2008; 9:803-812. [PubMed: 18346058]

5. Watkins EA, Wollan PC, Melton LJ, Yawn BP. A population in pain: report from the Olmsted County Health Study. Pain Med. 2008; 9:166-174. [PubMed: 18298699]

6. Borsook D, Becerra L, Hargreaves R. Biomarkers for chronic pain and analgesia. Part 1: the need, reality, challenges, and solutions. Discov Med. 2011; 11:197-207. [PubMed: 21447279]

7. Denk F, McMahon SB, Tracey I. Pain vulnerability: a neurobiological perspective. Nat Neurosci. 2014; 17:192-200. [PubMed: 24473267]

8. An excellent current review of factors that are associated with an increased risk of developing chronic pain. This review also includes some emerging concepts in genetics and epigenetics of pain

8. Abbott CA, Malik RA, van Ross ERE, et al. Prevalence and characteristics of painful diabetic neuropathy in a large community-based diabetic population in the U.K. Diabetes Care. 2011; 34:2220-2224. [PubMed: 21852677]

9. Balagué F, Mannion AF, Pellisé F, Cedraschi C. Nonspecific low back pain. Lancet. 2013; 379:482491. [PubMed: 21982256]

10. Kehlet H, Jensen TS, Woolf CJ. Persistent postsurgical pain: risk factors and prevention. Lancet. 2006; 367:1618-1625. [PubMed: 16698416]

11. Kehlet H, Rathmell JP. Persistent postsurgical pain: the path forward through better design of clinical studies. Anesthesiology. 2010; 112:514-515. [PubMed: 20124977]

12. Kehlet H, Roumen RM, Reinpold W, Miserez M. Invited commentary: persistent pain after inguinal hernia repair: what do we know and what do we need to know? Hernia. 2013; 17:293297. [PubMed: 23686405]

13. Mori $\mathrm{H}$, Watanabe $\mathrm{M}$, Akahane $\mathrm{M}$, et al. A case of venipuncture-induced complex regional pain syndrome. Nihon Igaku Hoshasen Gakkai Zasshi. 2002; 62:834-835. [PubMed: 12607953]

14. Horowitz SH. Venipuncture-induced causalgia: anatomic relations of upper extremity superficial veins and nerves, and clinical considerations. Transfusion. 2000; 40:1036-1040. [PubMed: 10988302]

15. Oaklander AL. Development of CRPS after shingles: it's all about location. Pain. 2012; 153:23092310. [PubMed: 23059053]

16. Andersen KG, Kehlet H. Persistent pain after breast cancer treatment: a critical review of risk factors and strategies for prevention. J Pain. 2011; 12:725-746. [PubMed: 21435953]

17ם. Belfer I, Schreiber KL, Shaffer JR, et al. Persistent postmastectomy pain in breast cancer survivors: analysis of clinical, demographic, and psychosocial factors. J Pain. 2013; 14:11851195. [PubMed: 23890847]

19. This manuscript summarizes risk factors for postmastectomy pain, which is a critical clinical concern

18. Sipila R, Estlander AM, Tasmuth T, et al. Development of a screening instrument for risk factors of persistent pain after breast cancer surgery. Br J Cancer. 2012; 107:1459-1466. [PubMed: 23093294]

21. This study describes a potential screening tool to help identify patients most at risk for developing chronic postmastectomy pain. This study makes an important contribution towards minimizing this risk 
19 . van Hecke O, Torrance N, Smith BH. Chronic pain epidemiology and its clinical relevance. Br J Anaesth. 2013; 111:13-18. [PubMed: 23794640]

23. A critical review of the global prevalance of chronic pain, and a clear description of the importance of this unmet medical need

20. Apkarian A, Bushnell M, Treede R-D, Zubieta J-K. Human brain mechanisms of pain perception and regulation in health and disease. Eur J Pain (London, England). 2005; 9:463-484.

21. Wager T, Atlas L, Lindquist M, et al. An fMRI-based neurologic signature of physical pain. $\mathrm{N}$ Engl J Med. 2013; 368:1388-1397. [PubMed: 23574118]

22. Liang M, Mouraux A, Hu L, Iannetti G. Primary sensory cortices contain distinguishable spatial patterns of activity for each sense. Nat Commun. 2013; 4:1979. [PubMed: 23752667]

23. Wood P, Schweinhardt P, Jaeger E, et al. Fibromyalgia patients show an abnormal dopamine response to pain. Eur J Neurosci. 2007; 25:3576-3582. [PubMed: 17610577]

24. Baliki MN, Geha PY, Fields HL, Apkarian AV. Predicting value of pain and analgesia: nucleus accumbens response to noxious stimuli changes in the presence of chronic pain. Neuron. 2010; 66:149-160. [PubMed: 20399736]

25. Baliki M, Petre B, Torbey S, et al. Corticostriatal functional connectivity predicts transition to chronic back pain. Nat Neurosci. 2012; 15:1117-1119. [PubMed: 22751038]

26. Hashmi J, Baliki M, Huang L, et al. Shape shifting pain: chronification of back pain shifts brain representation from nociceptive to emotional circuits. Brain. 2013; 136:2751-2768. [PubMed: 23983029]

27. Navratilova E, Xie J, King T, Porreca F. Evaluation of reward from pain relief. Ann N Y Acad Sci. 2013; 1282:1-11. [PubMed: 23496247]

32. This manuscript addresses the concept of pain relief as a homeopathic reward. Pain relief engages the reward/motivational circuitry

28. Price DD, Harkins SW. The affective-motivational dimension of pain. APS J. 1992; 1:229-239.

29. Fields HL. Pain: an unpleasant topic. Pain. 1999; (Suppl 6):S61-S69. [PubMed: 10491974]

30. Bair M, Wu J, Damush T, et al. Association of depression and anxiety alone and in combination with chronic musculoskeletal pain in primary care patients. Psychosom Med. 2008; 70:890-897. [PubMed: 18799425]

31. Gureje O. Comorbidity of pain and anxiety disorders. Curr Psychiatry Rep. 2008; 10:318-322. [PubMed: 18627670]

31. Borsook D, Edwards R, Elman I, et al. Pain and analgesia: the value of salience circuits. Progr Neurobiol. 2013; 104:93-105.

38. This study introduces the concept that how the brain assigns salience values to stimuli may contribute to chronic pain. Dysfunction of the salience network may contribute to chronic pain

33. Apkarian AV, Sosa Y, Sonty S, et al. Chronic back pain is associated with decreased prefrontal and thalamic gray matter density. J Neurosci. 2004; 24:10410-10415. [PubMed: 15548656]

34. Elman I, Borsook D, Volkow N. Pain and suicidality: insights from reward and addiction neuroscience. Progr Neurobiol. 2013; 109:1-27.

41. Social and emotional loss and physical pain share common neural systems, which provides a link to suicidality in pain patients

35. Finnerup NB, Sindrup SH, Jensen TS. The evidence for pharmacological treatment of neuropathic pain. Pain. 2010; 150:573-581. [PubMed: 20705215]

36. Backonja MM, Irving G, Argoff C. Rational multidrug therapy in the treatment of neuropathic pain. Curr Pain Headache Rep. 2006; 10:34-38. [PubMed: 16499828]

37. Leknes S, Tracey I. A common neurobiology for pain and pleasure. Nat Rev Neurosci. 2008; 9:314-320. [PubMed: 18354400]

38. Bushnell MC, Ceko M, Low LA. Cognitive and emotional control of pain and its disruption in chronic pain. Nat Rev Neurosci. 2013; 14:502-511. [PubMed: 23719569]

46. A critical and timely review of factors governing emotional and cognitive aspects of pain. These factors play an important role in development of chronic pain

39. Tracey I. Getting the pain you expect: mechanisms of placebo, nocebo and reappraisal effects in humans. Nat Med. 2010; 16:1277-1283. [PubMed: 20948533] 
40. Tracey I, Johns E. The pain matrix: reloaded or reborn as we image tonic pain using arterial spin labelling. Pain. 2010; 148:359-360. [PubMed: 20080346]

41. Bingel U, Tracey I. Imaging CNS modulation of pain in humans. Physiology (Bethesda). 2008; 23:371-380. [PubMed: 19074744]

42. Reynolds DV. Surgery in the rat during electrical analgesia induced by focal brain stimulation. Science. 1969; 164:444-445. [PubMed: 4887743]

43. Tsou K, Jang CS. Studies on the site of analgesic action of morphine by intracerebral microinjection. Sci Sin. 1964; 13:1099-1109. [PubMed: 14196479]

44. Hosobuchi Y, Adams JE, Linchitz R. Pain relief by electrical stimulation of the central gray matter in humans and its reversal by naloxone. Science. 1977; 197:183-186. [PubMed: 301658]

45. Richardson DE, Akil H. Pain reduction by electrical brain stimulation in man. Part 1: Acute administration in periaqueductal and periventricular sites. J Neurosurg. 1977; 47:178-183. [PubMed: 327030]

46. Richardson DE, Akil H. Long term results of periventricular gray self-stimulation. Neurosurgery. 1977; 1:199-202. [PubMed: 308192]

47. Yeung JC, Yaksh TL, Rudy TA. Concurrent mapping of brain sites for sensitivity to the direct application of morphine and focal electrical stimulation in the production of antinociception in the rat. Pain. 1977; 4:23-40. [PubMed: 927879]

48. Yaksh TL, Rudy TA. Narcotic analgesics: CNS sites and mechanisms of action as revealed by intracerebral injection techniques. Pain. 1978; 4:299-359. [PubMed: 25403]

49. Lewis VA, Gebhart GF. Morphine-induced and stimulation-produced analgesias at coincident periaqueductal central gray loci: evaluation of analgesic congruence, tolerance, and crosstolerance. Exp Neurol. 1977; 57:934-955. [PubMed: 923683]

50. Lewis VA, Gebhart GF. Evaluation of the periaqueductal central gray (PAG) as a morphinespecific locus of action and examination of morphine-induced and stimulation-produced analgesia at coincident PAG loci. Brain Res. 1977; 124:283-303. [PubMed: 191150]

51. Gao K, Kim YH, Mason P. Serotonergic pontomedullary neurons are not activated by antinociceptive stimulation in the periaqueductal gray. J Neurosci. 1997; 17:3285-3292. [PubMed: 9096161]

52. Waters AJ, Lumb BM. Inhibitory effects evoked from both the lateral and ventrolateral periaqueductal grey are selective for the nociceptive responses of rat dorsal horn neurones. Brain Res. 1997; 752:239-249. [PubMed: 9106463]

53. Helmstetter FJ, Tershner SA, Poore LH, Bellgowan PS. Antinociception following opioid stimulation of the basolateral amygdala is expressed through the periaqueductal gray and rostral ventromedial medulla. Brain Res. 1998; 779:104-118. [PubMed: 9473612]

54. Gauriau C, Bernard JF. Pain pathways and parabrachial circuits in the rat. Exp Physiol. 2002; 87:251-258. [PubMed: 11856971]

55. Petrovic P, Kalso E, Petersson KM, Ingvar M. Placebo and opioid analgesia: imaging a shared neuronal network. Science. 2002; 295:1737-1740. [PubMed: 11834781]

56. Eippert F, Bingel U, Schoell ED, et al. Activation of the opioidergic descending pain control system underlies placebo analgesia. Neuron. 2009; 63:533-543. [PubMed: 19709634]

57. Fields, HL.; Basbaum, AI.; Heinricher, MM. Central nervous system mechanisms of pain modulation. In: McMahon, SB.; Koltzenburg, M., editors. Textbook of pain. Churchill Livingstone; Edinburgh: 2005. p. 125-142.

58. Behbehani MM, Fields HL. Evidence that an excitatory connection between the periaqueductal gray and nucleus raphe magnus mediates stimulation produced analgesia. Brain Res. 1979; 170:85-93. [PubMed: 223721]

59. Vanegas H, Schaible HG. Descending control of persistent pain: inhibitory or facilitatory? Brain Res Rev. 2004; 46:295-309. [PubMed: 15571771]

60. Heinricher MM, Tavares I, Leith JL, Lumb BM. Descending control of nociception: specificity, recruitment and plasticity. Brain Res Rev. 2009; 60:214-225. [PubMed: 19146877]

61. Burgess SE, Gardell LR, Ossipov MH, et al. Time-dependent descending facilitation from the rostral ventromedial medulla maintains, but does not initiate, neuropathic pain. J Neurosci. 2002; 22:5129-5136. [PubMed: 12077208] 
62. Gardell LR, Vanderah TW, Gardell SE, et al. Enhanced evoked excitatory transmitter release in experimental neuropathy requires descending facilitation. J Neurosci. 2003; 23:8370-8379. [PubMed: 12967999]

63. Zhang W, Gardell S, Zhang D, et al. Neuropathic pain is maintained by brainstem neurons coexpressing opioid and cholecystokinin receptors. Brain. 2009; 132:778-787. [PubMed: 19050032]

64. Lagraize SC, Guo W, Yang K, et al. Spinal cord mechanisms mediating behavioral hyperalgesia induced by neurokinin-1 tachykinin receptor activation in the rostral ventromedial medulla. Neuroscience. 2010; 171:1341-1356. [PubMed: 20888891]

65. Guo W, Robbins MT, Wei F, et al. Supraspinal brain-derived neurotrophic factor signaling: a novel mechanism for descending pain facilitation. J Neurosci. 2006; 26:126-137. [PubMed: 16399679]

66. Bee LA, Dickenson AH. Rostral ventromedial medulla control of spinal sensory processing in normal and pathophysiological states. Neuroscience. 2007; 147:786-793. [PubMed: 17570596]

67. Bee LA, Dickenson AH. Descending facilitation from the brainstem determines behavioural and neuronal hypersensitivity following nerve injury and efficacy of pregabalin. Pain. 2008; 140:209223. [PubMed: 18809257]

68. King T, Vera-Portocarrero L, Gutierrez T, et al. Unmasking the tonic-aversive state in neuropathic pain. Nat Neurosci. 2009; 12:1364-1366. [PubMed: 19783992]

68. De Felice M, Eyde N, Dodick D, et al. Capturing the aversive state of cephalic pain preclinically. 2013; 74:257-265.

78. This recent study describes how ongoing cephalic pain motivates animals to seek relief. Pain relief activates the motivational/reward circuit

70. Lee MC, Zambreanu L, Menon DK, Tracey I. Identifying brain activity specifically related to the maintenance and perceptual consequence of central sensitization in humans. J Neurosci. 2008; 28:11642-11649. [PubMed: 18987200]

71. Kato G, Yasaka T, Katafuchi T, et al. Direct GABAergic and glycinergic inhibition of the substantia gelatinosa from the rostral ventromedial medulla revealed by in vivo patch-clamp analysis in rats. J Neurosci. 2006; 26:1787-1794. [PubMed: 16467527]

72. Hossaini M, Goos JA, Kohli SK, Holstege JC. Distribution of glycine/GABA neurons in the ventromedial medulla with descending spinal projections and evidence for an ascending glycine/ GABA projection. PLoS One. 2012; 7:e35293. [PubMed: 22558137]

73. Wei F, Dubner R, Zou S, et al. Molecular depletion of descending serotonin unmasks its novel facilitatory role in the development of persistent pain. J Neurosci. 2010; 30:8624-8636. [PubMed: 20573908]

74. Foo H, Mason P. Brainstem modulation of pain during sleep and waking. Sleep Med Rev. 2003; 7:145-154. [PubMed: 12628215]

75. Morgan MM, Whittier KL, Hegarty DM, Aicher SA. Periaqueductal gray neurons project to spinally projecting GABAergic neurons in the rostral ventromedial medulla. Pain. 2008; 140:376386. [PubMed: 18926635]

76. Winkler CW, Hermes SM, Chavkin CI, et al. Kappa opioid receptor (KOR) and GAD67 immunoreactivity are found in OFF and NEUTRAL cells in the rostral ventromedial medulla. $\mathrm{J}$ Neurophysiol. 2006; 96:3465-3473. [PubMed: 17005613]

77. Suzuki R, Rygh LJ, Dickenson AH. Bad news from the brain: descending 5-HT pathways that control spinal pain processing. Trends Pharmacol Sci. 2004; 25:613-617. [PubMed: 15530638]

78. Dogrul A, Ossipov MH, Porreca F. Differential mediation of descending pain facilitation and inhibition by spinal 5HT-3 and 5HT-7 receptors. Brain Res. 2009; 1280:52-59. [PubMed: 19427839]

79. Sasaki M, Obata H, Kawahara K, et al. Peripheral 5-HT2A receptor antagonism attenuates primary thermal hyperalgesia and secondary mechanical allodynia after thermal injury in rats. Pain. 2006; 122:130-136. [PubMed: 16527395]

80. Green GM, Scarth J, Dickenson A. An excitatory role for 5-HT in spinal inflammatory nociceptive transmission; state-dependent actions via dorsal horn 5-HT(3) receptors in the anaesthetized rat. Pain. 2000; 89:81-88. [PubMed: 11113296]

81. Bannister K, Bee LA, Dickenson AH. Preclinical and early clinical investigations related to monoaminergic pain modulation. Neurotherapeutics. 2009; 6:703-712. [PubMed: 19789074] 
82. Rahman W, Bauer CS, Bannister K, et al. 2009; 5:45.

83. Brenchat A, Romero L, Garcia M, et al. 5-HT7 receptor activation inhibits mechanical hypersensitivity secondary to capsaicin sensitization in mice. Pain. 2009; 141:239-247. [PubMed: 19118950]

84. Bajic D, Proudfit HK. Projections of neurons in the periaqueductal gray to pontine and medullary catecholamine cell groups involved in the modulation of nociception. J Comp Neurol. 1999; 405:359-379. [PubMed: 10076931]

85. Bruinstroop E, Cano G, Vanderhorst VGJM, et al. Spinal projections of the A5, A6 (locus coeruleus), and A7 noradrenergic cell groups in rats. J Comp Neurol. 2012; 520:1985-2001. [PubMed: 22173709]

86. Holden JE, Proudfit HK. Enkephalin neurons that project to the A7 catecholamine cell group are located in nuclei that modulate nociception: ventromedial medulla. Neuroscience. 1998; 83:929_ 947. [PubMed: 9483575]

87. Pertovaara A. Noradrenergic pain modulation. Prog Neurobiol. 2006; 80:53-83. [PubMed: 17030082]

88. Budai D, Harasawa I, Fields HL. Midbrain periaqueductal gray (PAG) inhibits nociceptive inputs to sacral dorsal horn nociceptive neurons through alpha2-adrenergic receptors. J Neurophysiol. 1998; 80:2244-2254. [PubMed: 9819240]

89. Ossipov MH, Harris S, Lloyd P, Messineo E. An isobolographic analysis of the antinociceptive effect of systemically and intrathecally administered combinations of clonidine and opiates. J Pharmacol Exp Ther. 1990; 255:1107-1116. [PubMed: 2262895]

90. Ossipov MH, Harris S, Lloyd P, et al. Antinociceptive interaction between opioids and medetomidine: systemic additivity and spinal synergy. Anesthesiology. 1990; 73:1227-1235. [PubMed: 1978990]

91. Fairbanks CA, Stone LS, Kitto KF, et al. alpha(2C)-Adrenergic receptors mediate spinal analgesia and adrenergic-opioid synergy. J Pharmacol Exp Ther. 2002; 300:282-290. [PubMed: 11752127]

92. Holden JE, Schwartz EJ, Proudfit HK. Microinjection of morphine in the A7 catecholamine cell group produces opposing effects on nociception that are mediated by alpha1- and alpha2adrenoceptors. Neuroscience. 1999; 91:979-990. [PubMed: 10391476]

93. Eisenach JC, Hood DD, Curry R. Intrathecal, but not intravenous, clonidine reduces experimental thermal or capsaicin-induced pain and hyperalgesia in normal volunteers. Anesth Analg. 1998; 87:591-596. [PubMed: 9728835]

94. Eisenach JC, DuPen S, Dubois M, et al. Epidural clonidine analgesia for intractable cancer pain. The Epidural Clonidine Study Group. Pain. 1995; 61:391-399.

95. Muto Y, Sakai A, Sakamoto A, Suzuki H. Activation of NK1 receptors in the locus coeruleus induces analgesia through noradrenergic-mediated descending inhibition in a rat model of neuropathic pain. Br J Pharmacol. 2012; 166:1047-1057. [PubMed: 22188400]

96. Ma W, Eisenach JC. Chronic constriction injury of sciatic nerve induces the up-regulation of descending inhibitory noradrenergic innervation to the lumbar dorsal horn of mice. Brain Res. 2003; 970:110-118. [PubMed: 12706252]

97. Omiya Y, Yuzurihara M, Suzuki Y, et al. Role of alpha2-adrenoceptors in enhancement of antinociceptive effect in diabetic mice. Eur J Pharmacol. 2008; 592:62-66. [PubMed: 18625215]

98. Arnold LM. Duloxetine and other antidepressants in the treatment of patients with fibromyalgia. Pain Med. 2007; 8(Suppl 2):S63-S74. [PubMed: 17714117]

99. Smith T, Nicholson RA. Review of duloxetine in the management of diabetic peripheral neuropathic pain. Vasc Health Risk Manag. 2007; 3:833-844. [PubMed: 18200804]

100. Di Franco M, Iannuccelli C, Atzeni F, et al. Pharmacological treatment of fibromyalgia. Clin Exp Rheumatol. 2010; 281:S110-S116. [PubMed: 21176430]

101․ Raffa RB, Buschmann H, Christoph T, et al. Mechanistic and functional differentiation of tapentadol and tramadol. Expert Opin Pharmacother. 2012; 13:1437-1449. [PubMed: 22698264]

111. A timely and critical review of analgesics that activate the opioid and noradrenergic pain inhibitory systems 
102. You HJ, Lei J, Sui MY, et al. Endogenous descending modulation: spatiotemporal effect of dynamic imbalance between descending facilitation and inhibition of nociception. J Physiol. 2010; 588:4177-4188. [PubMed: 20837643]

103. Ren K, Dubner R. Descending modulation in persistent pain: an update. Pain. 2002; 100:1-6. [PubMed: 12435453]

104. Xu M, Kontinen VK, Kalso E. Endogenous noradrenergic tone controls symptoms of allodynia in the spinal nerve ligation model of neuropathic pain. Eur J Pharmacol. 1999; 366:41-45.

[PubMed: 10064150]

105. De Felice M, Sanoja R, Wang R, et al. Engagement of descending inhibition from the rostral ventromedial medulla protects against chronic neuropathic pain. Pain. 2011; 152:2701-2709. [PubMed: 21745713]

106ロ. Hughes SW, Hickey L, Hulse RP, et al. Endogenous analgesic action of the pontospinal noradrenergic system spatially restricts and temporally delays the progression of neuropathic pain following tibial nerve injury. Pain. 2013; 154:1680-1690. [PubMed: 23707289]

117. This study shows that the descending noradrenergic system can offer protection against chronic pain. This is especially significant as many drugs effective against neuropathic pain engage or mimic this system

107. Sevcik MA, Jonas BM, Lindsay TH, et al. Endogenous opioids inhibit early-stage pancreatic pain in a mouse model of pancreatic cancer. Gastroenterology. 2006; 131:900-910. [PubMed: 16952558]

108. Lewis GN, Heales L, Rice DA, et al. Reliability of the conditioned pain modulation paradigm to assess endogenous inhibitory pain pathways. Pain Res Manag. 2012; 17:98-102. [PubMed: 22518372]

109. Martel MO, Wasan AD, Edwards RR. Sex differences in the stability of conditioned pain modulation (CPM) among patients with chronic pain. Pain Med. 2013; 14:1757-1768. [PubMed: 23924369]

121. A well designed analysis of the lability of CPM, and the role of sex differences

110 Granovsky Y, Yarnitsky D. Personalized pain medicine: the clinical value of psychophysical assessment of pain modulation profile. Rambam Maimonides Med J. 2013; 4:e0024. [PubMed: 24228167]

123. Convincing arguments for the role of emotional and psychological factors in pain perception of chronic pain patients are presented.

111 Granovsky Y. Conditioned pain modulation: a predictor for development and treatment of neuropathic pain. Current pain and headache reports. 2013; 17:361. [PubMed: 23943407]

125. This manuscript introduces the concept that mechanisms underlying CPM can be to predict and treat neuropathic pain. This study points to potential therapeutic avenues.

112. Ablin JN, Buskila D. Fibromyalgia syndrome: novel therapeutic targets. Maturitas. 2013; 75:335-340. [PubMed: 23742873]

127. An excellent review of potential mechanisms of fibromyalgia and mechanisms that may be exploited to treat this condition.

113. Bouwense SA, Olesen SS, Drewes AM, et al. Is altered central pain processing related to disease stage in chronic pancreatitis patients with pain? An exploratory study. PLoS One. 2013; 8:e55460. [PubMed: 23405154]

129. This study provides evidence that increased pain associated with pancreatitis is related to the degree of loss of endogenous pain inhibition.

114 Williams AE, Heitkemper M, Self MM, et al. Endogenous inhibition of somaticpain is impaired in girls with irritable bowel syndrome compared with healthy girls. J Pain. 2013; 14:921-930. [PubMed: 23685184]

131. This study relates loss of CPM to the development of IBS and to the pain associated with this

115 . Jarrett ME, Shulman RJ, Cain KC, et al. Conditioned pain modulation in women with irritable bowel syndrome. Biol Res Nurs. 2014 [Epub ahead of print].

133. This article provides evidence that IBS is due to a deficit of endogenous pain inhibitory systems 
116 Meeus M, Hermans L, Ickmans K, et al. Endogenous pain modulation in response to exercise in patients with rheumatoid arthritis, patients with chronic fatigue syndrome and comorbid fibromyalgia, and healthy controls: a double-blind randomized controlled trial. Pain Pract. 2014 [Epub ahead of print].

135. This article reporting that several chronic pain states are maintained by deficits of endogenous pain inhibitory systems (CPMs) is strengthened by the randomized double-blind design

117. Olesen SS, Frokjaer JB, Lelic D, et al. Pain-associated adaptive cortical reorganisation in chronic pancreatitis. Pancreatology. 2010; 10:742-751. [PubMed: 21273802]

118. Arendt-Nielsen L, Nie H, Laursen MB, et al. Sensitization in patients with painful knee osteoarthritis. Pain. 2010; 149:573-581. [PubMed: 20418016]

119. Le Bars D, Dickenson AH, Besson JM. Diffuse noxious inhibitory controls (DNIC). II. Lack of effect on nonconvergent neurones, supraspinal involvement and theoretical implications. Pain. 1979; 6:305-327. [PubMed: 460936]

120. Lima D, Albino-Teixeira A, Tavares I. The caudal medullary ventrolateral reticular formation in nociceptive-cardiovascular integration. An experimental study in the rat. Exp Physiol. 2002; 87:267-274. [PubMed: 11856973]

121. Leite-Almeida H, Valle-Fernandes A, Almeida A. Brain projections from the medullary dorsal reticular nucleus: an anterograde and retrograde tracing study in the rat. Neuroscience. 2006; 140:577-595. [PubMed: 16563637]

122. Okada-Ogawa A, Porreca F, Meng ID. Sustained morphine-induced sensitization and loss of diffuse noxious inhibitory controls in dura-sensitive medullary dorsal horn neurons. J Neurosci. 2009; 29:15828-15835. [PubMed: 20016098] 


\section{KEY POINTS}

- Multiple regions of the brain have been shown to be associated with nociceptor activation. These regions overlap with those that process emotion and motivation and that likely mediate the affective (aversive) aspects of pain.

- Human and animal studies employing pharmacologic and neurochemical means have identified bidirectional pain modulatory systems arising from pontomedullary sites. These regions engage descending noradrenergic and serotonergic systems that can enhance or attenuate nociceptive inputs at the spinal level. Emerging evidence indicates that circuits involved in emotional learning can influence the activity of these descending pain modulatory systems.

- Recent studies suggest that patients with established chronic pain tend to demonstrate an attenuated endogenous pain inhibitory process when compared with pain-free individuals. Engagement of descending inhibition may represent an endogenous mechanism that protects against pain chronification. Patients with dysfunctional pain (pain in the absence of apparent injury) show an apparent loss of descending inhibition (i.e. conditioned pain modulation, DNIC).

- Apparent loss of descending inhibition may reflect enhanced descending facilitation or both. Drugs effective in the treatment of chronic pain often act by mimicking the actions of endogenous descending inhibition suggesting that new pharmacological treatments may be discovered by understanding the specifics of descending pain modulatory circuits. 